\title{
Comparative study on direct and indirect bracket bonding techniques regarding time length and bracket detachment
}

\author{
Jefferson Vinicius Bozelli1, Renato Bigliazzi ${ }^{1}$, Helga Adachi Medeiros Barbosa², \\ Cristina Lucia Feijo Ortolani3, Francisco Antonio Bertoz ${ }^{4}$, Kurt Faltin Junior ${ }^{3}$
}

Objective: The aim of this study was to assess the time spent for direct (DBB - direct bracket bonding) and indirect (IBB - indirect bracket bonding) bracket bonding techniques. The time length of laboratorial (IBB) and clinical steps (DBB and IBB) as well as the prevalence of loose bracket after a 24-week follow-up were evaluated. Methods: Seventeen patients ( 7 men and 10 women) with a mean age of 21 years, requiring orthodontic treatment were selected for this study. A total of 304 brackets were used (151 DBB and 153 IBB). The same bracket type and bonding material were used in both groups. Data were submitted to statistical analysis by Wilcoxon non-parametric test at $5 \%$ level of significance. Results: Considering the total time length, the IBB technique was more time-consuming than the DBB $(\mathrm{p}<0.001)$. However, considering only the clinical phase, the IBB took less time than the DBB $(\mathrm{p}<0.001)$. There was no significant difference $(p=0.910)$ for the time spent during laboratorial positioning of the brackets and clinical session for IBB in comparison to the clinical procedure for DBB. Additionally, no difference was found as for the prevalence of loose bracket between both groups. Conclusion: the IBB can be suggested as a valid clinical procedure since the clinical session was faster and the total time spent for laboratorial positioning of the brackets and clinical procedure was similar to that of DBB. In addition, both approaches resulted in similar frequency of loose bracket.

Keywords: Corrective orthodontics. Orthodontic brackets. Dental bonding. Dental detachment.

Objetivo: avaliar o tempo necessário para realização da colagem de braquetes pelas técnicas direta (CDB) e indireta (CIB), mensurando o tempo despendido entre a parte laboratorial (CIB) e a parte clínica (CDB e CIB), e a prevalência de descolamentos durante o período de observação de 24 semanas. Métodos: dezessete pacientes (7 homens e 10 mulheres), com idade média de 21 anos, com necessidade de tratamento ortodôntico, foram selecionados para participar desse estudo. Foram utilizados um total de 304 braquetes, sendo que 151 foram colados pela técnica de CDB e 153 pela CIB, com o mesmo tipo de braquete e material de colagem. Os dados foram submetidos ao teste não paramétrico de Wilcoxon, com significância de 5\%. Resultados: o tempo total para realização da CIB foi maior em relação à $\mathrm{CDB}(\mathrm{p}<0,001)$. Levando em consideração apenas a fase clínica, foi observado que o tempo para CIB foi menor em relação a $\mathrm{CDB}(\mathrm{p}<0,001)$. A comparação entre o tempo despendido para o posicionamento dos braquetes em laboratório mais o tempo em clínica para CIB com o tempo em clínica para a CDB revelou que não houve diferença significativa $(p=0,910)$, nem tampouco quanto à prevalência de descolamento dos braquetes. Conclusão: a CIB apresenta-se como uma utilidade clínica singular, pois o tempo em clínica foi menor que o da CDB. O tempo despendido no posicionamento dos braquetes no laboratório e de execução clínica da CIB foi semelhante ao tempo gasto pela $\mathrm{CDB}$, a quantidade de descolamentos foi semelhante entre as técnicas.

Palavras-chave: Ortodontia corretiva. Braquetes ortodônticos. Colagem dentária. Descolagem dentária.

» Patients displayed in this article previously approved the use of their facial and intraoral photographs.

${ }^{1}$ Associate Professor, Department of Orthodontics, Paulista University (UNIP).

${ }^{2} \mathrm{MSc}$ in Orthodontics, UNIP.

${ }^{3}$ Full professor, Department of Orthodontics Paulista University (UNIP).

${ }^{4}$ Full professor, Department of Orthodontics, State University of São Paulo (UNESP).

" The authors report no commercial, proprietary or financial interest in the products or companies described in this article.
How to cite this article: Bozelli JV, Bigliazzi R, Barbosa HAM, Ortolani CLF, Bertoz FA, Faltin Junior K. Comparative study on direct and indirect bracket bonding techniques regarding time length and bracket detachment. Dental Press J Orthod. 2013 Nov-Dec;18(6):51-7.

Submitted: March 02, 2011 - Revised and accepted: February 02, 2012

Contact address: Renato Bigliazzi

Faculdade de Odontologia de Araçatuba

Rua José Bonifácio, 1193 - Araçatuba/SP - CEP: 16.015-050

E-mail: bigliazzir@hotmail.com 


\section{INTRODUCTION}

Bonding accessories on tooth surface revolutionized Orthodontics,making the clinical results easier and more reliable. It solved some of the difficulties encountered in orthodontic banding procedures; such as professional skills, patient's discomfort resulting from separators and banding, risk to periodontal diseases and cavities, better esthetic acceptance, material cost and the time spent to make and insert the bands..$^{1,2,3}$ Thus, directly bonding accessories on the enamel became the most common technique used by orthodontists considering that effective bracket bonding is essential for appropriate orthodontic mechanics. This approach also reduces treatment length and avoids rebonding caused by inappropriate positioning and/or loose bracket. ${ }^{4}$ On the other hand, precise bracket bonding relies on the professional's experience and accuracy of bonding procedures.

Aiming at improving precision and attaining excellence in orthodontic procedures, Silverman et $\mathrm{al}^{5}$ developed the indirect bracket bonding (IBB) technique. In this approach, the brackets are previously positioned on casts with water-soluble or intermediary adhesives, and then transferred to the mouth by means of an individual tray. For these authors, the direct bracket bonding (DBB) technique is time-consuming and the correct positioning of the brackets is difficult to achieve clinically.

Thus, the aim of this in vivo study was to compare the direct and indirect (tray transferred with fusible glue $^{6}$ ) bracket bonding techniques regarding the time spent for laboratorial (IBB) and clinical (IBB and $\mathrm{DBB})$ steps and its correlation for the IBB as well as the prevalence of loose bracket.

\section{MATERIAL AND METHODS}

\section{Patient selection and study design}

Seventeen patients ( 7 men and 10 women) with a mean age of 21 years, who required orthodontic treatment, were selected for the present prospective study conducted at the college of Dentistry of Paulista University - UNIP/SP from March to June, 2008. Treatment lasted for 2 years. Each subject signed a written informed consent before entering the cohort which was approved by the Paulista University-UNIP/SP Institutional Review board (number 122/05 CEP/ICS/UNIP).
Upper and lower dental casts of each patient were obtained after impression with irreversible hydrocolloid (Jeltrate, Dentsply, Brazil) manipulated according to the manufacturer's instructions. The impressions were rinsed with water for 1 minute, airdried and then poured with dental stone (Dentsply, Brazil). After stone crystallization (40 minutes), the casts were removed from the impression trays and trimmed. The IBB technique requires working casts with minor irregularities.

\section{Laboratorial step - Fabrication of transferring trays}

All laboratorial procedures were conducted by the same operator according to an accurate methodology. Table 1 presents all the acronyms used in this study for laboratorial and clinical steps timings.

The tooth long axis and the gingival-occlusal height of the brackets tubes were determined manually in all patients for correct bracket positioning. The time spent during this procedure was measured by the software Palmaryclock ${ }^{\circledR}$ v. 23 (Palmarysoft 20022004) downloaded into Palm Tungsten $T$ device $\left(\right.$ Palm $^{\circledR}$ - Brazil) and recorded (TL1 - Time spent to determine the height and tooth long axis in the maxilla and mandible during laboratorial step).

The study by Aguirre et $\mathrm{al}^{7}$ was used as reference to determine the protocol for the IBB technique conducted in the present study. The arches were divided into two sections: upper and lower right side (DBB) and upper and lower left side (IBB), and these sides were chosen based on the fact that they enabled direct visualization of bracket bonding, since a righthanded operator conducted the research by himself. The bonding procedure was initiated at the left central incisor and finished at the left second premolar in both the maxilla and mandible. Water-soluble glue was used and any excess material draining from the brackets base was removed. The Morelli ${ }^{\circledR}$ (0.018 x 0.030-in, Bioprogressive technique) metallic brackets were selected for treating all patients.

The time spent for bonding the brackets on the working casts was also measured and recorded (TL2, time spent for bonding the brackets in maxillary and mandibular casts). However, the time spent for clinical bonding was measured for each tooth individually and then summed up to obtain the total time for 
Table 1 - Acronyms used for different laboratorial and clinical time

\begin{tabular}{cl}
\hline TL1 & Time spent to determine the height and tooth long axis during laboratorial step in maxilla and mandible \\
\hline TL2 & Time spent for bracket bonding in the cast in maxilla and mandible \\
\hline TL3 & Time spent for fabrication of transferring trays in maxilla and mandible \\
\hline TLt & Total laboratorial time in maxilla and mandible \\
\hline TCl1 & Time spent with IBB during clinical step in maxilla and mandible \\
\hline TCl2 & Time spent for removal and cleaning of the IBB area in maxilla and mandible \\
\hline TClt & Total clinical time for IBB in maxilla and mandible \\
\hline TCD1 & Time spent with DBB in maxilla and mandible \\
\hline TCD2 & Time spent for cleaning of the DBB area in maxilla and mandible \\
TCDt & Total time for DBB in maxilla and mandible \\
TPBt & Time spent for laboratorial positioning of the brackets \\
\hline
\end{tabular}

bonding performed in each hemi-arch. To make the transferring tray (Figs 1 and 2), hot melt adhesive (slightly fluid) was applied to each bracket and to the vestibular surface of each tooth, following the same bonding sequence for the model, in other words, the bonding started from tooth \#21 to \#25, then from $\# 31$ up to \#35. After that, additional glue was inserted on the incisal and occlusal surfaces of the teeth in order to make a less flexible and harder tray. The time spent for making the transferring trays was also measured and recorded (TL3, time spent for fabrication of the upper and lower transferring trays).

After solidification of the silicone glue (hot melt glue), the casts were hydrated for 1 minute so that the glue could be dissolved and, then, the brackets were transferred with the transferring trays, concluding the laboratorial step of the IBB approach. The total laboratorial time included the time spent for bracket bonding and fabrication/cleaning of the transferring trays (TLt - total laboratorial time for maxilla and mandible), which means that TLt=TL1+TL2+TL3.

\section{Clinical step}

The IBB technique was conducted at the upper and lower left side while the right side was selected for the DBB technique (Fig 3). The procedure was timed after prophylaxis (pumice and rubber tip) and enamel etching performed with 37\% of phosphoric acid (RMO) following the manufacturer's instructions since the time spent for this initial step was similar for both techniques. The self-curing resin (paste + liquid - No Mix) Mono Lock $2\left(\mathrm{RMO}^{\circledR}\right)$ was selected for bonding.

For IBB, the etched teeth and transferring trays were dried in order to maintain the chemical and physical properties of the adhesive system. Then, the activator of the bonding material (liquid) was applied on the enamel and brackets mesh positioned into the transferring tray. After that, resin (paste) was inserted on the brackets mesh that was positioned at the hemiarch of the patient.

The whole process from application of the activator (liquid) on enamel to positioning of the transferring tray

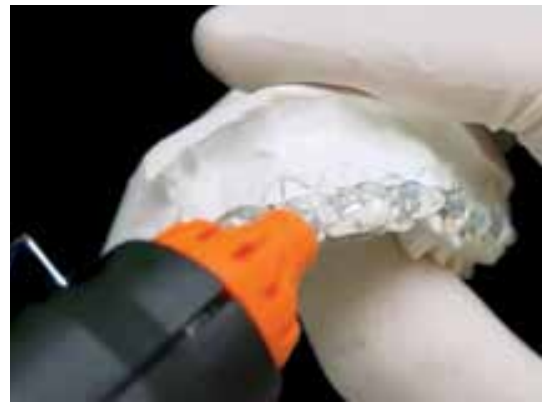

Figure 1 - Fabrication of the transferring tray.

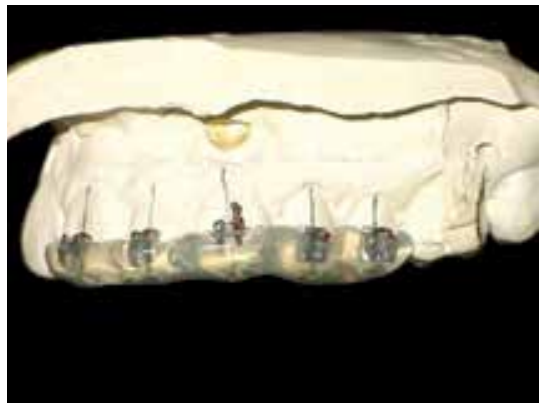

Figure 2 - Transferring trays with ideal dimension and thickness.

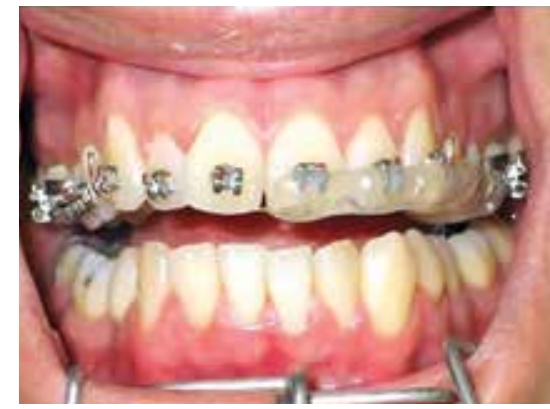

Figure 3 - Example of brackets bonded by means of DBB and IBB techniques in the maxilla 
was timed and recorded (TCI1 - time spent for clinical session of IBB technique in maxilla and mandible).

The DBB approach was conducted in sequence, from the right central incisor to the right second premolar in both jaws. The whole process of the direct technique was timed (TCD1 - time spent with the DBB technique in maxilla and mandible). The bonding steps were similar to those of the IBB approach: Drying of the etched teeth, application of activator on enamel and bracket mesh, insertion of resin on brackets mesh, and positioning it on the teeth. The positioning respected the height of each tooth (Boone bracket positioning gauge).

After DBB, the removal and cleaning of the IBB area was conducted. The transferring tray and the excess resin were removed using the tip of the rubber band insertion tool and a bur for enamel (3M Unitek - California), respectively. This step was also timed and recorded (TCI2 - time spent for removal and cleaning of the IBB area in maxilla and mandible).

The total clinical time for the IBB approach was represented by the time spent for IBB and cleaning step (TCIt - total clinical time spent for IBB technique in maxilla and mandible), which means TCIt $=$ TCI1+TCI2.

The cleaning of the DBB area was also conducted using a bur to remove excess resin on the enamel surface (3M Unitek - California). This process was also timed and recorded (TCD2 - time spent for cleaning of the DBB area in maxilla and mandible).

The total clinical time for the DBB approach was represented by the time spent for DBB (tooth by tooth) and cleaning step (TCDt - total clinical time spent for DBB technique in maxilla and mandible), which means TCDt $=$ TCD1+TCD2.

After the clinical step, the patient was submitted to correction of dental positioning through orthodontic mechanics.

\section{Follow-up}

The patients were evaluated every 4 weeks in order to have the loose brackets assessed. A 24-week follow-up was accomplished, representing 6 monthly appointments. All detachments were noted on each patient's record taking into account the side (right and left), arch (maxilla and mandible), date (day/month/year), and position (tooth). The loose brackets were replaced by new brackets bonded according to the DBB technique.

\section{Statistical analysis}

The Wilcoxon non-parametric test was applied for comparison between the periods, since assumption of data normality was rejected. A significance level of $5 \%$ was used in all tests.

\section{RESULTS}

Based on the statistical analysis carried out, the following results were obtained.

\section{Evaluation of time spent for bracket bonding with DBB and IBB techniques}

Considering the total time spent with IBB (TLt+TCIt) and DBB (TCDt) in both jaws, the Wilcoxon test revealed significant difference $(\mathrm{p}<0.001)$ between the groups, which means that IBB was more time-consuming than DBB (Table 2 and Fig 4). However, when only the clinical step was considered, a statistically significant difference $(p<0.001)$ was also observed, but IBB (TCIt) was less time-consuming than DBB (TCDt) (Table 3 and Fig 5).

There was no significant difference $(p=0.910)$ for the time spent during laboratorial positioning of the brackets $(\mathrm{TPBt}=\mathrm{TL} 1+\mathrm{TL} 2)$ and clinical step with IBB (TCIt) in comparison to the clinical time with DBB (TCDt) (Table 4 and Fig 6).

\section{Total number of brackets detached with IBB and DBB techniques}

After bracket bonding performed with IBB and DBB approaches in both jaws, a 24-week follow-up was conducted for all patients in order to check potential loose bracket. A total of 304 brackets were inserted, including 151 brackets with DBB technique (70 brackets in maxilla and 81 in mandible) and 153 brackets with IBB (72 brackets in maxilla and 81 in mandible). At the end, a total of 18 brackets were detached, which represents 5.92\% (Table 5 and Fig 7).

Maxilla exhibited a lower number of loose brackets $(22.22 \%)$ in comparison to the mandible (77.78\%), including 4 detachments in the upper arch (3 for IBB and 1 for $\mathrm{DBB}$ ) and 14 occurrences in the lower arch (8 for IBB and 6 for DBB).

\section{DISCUSSION}

The results of the present study demonstrated that the total time spent with the IBB technique (laboratorial 
Table 2 - Total time spent with IBB (TLt+TCIt) and DBB (TCDt), in both arches

\begin{tabular}{cccccc}
\hline Time & $\mathbf{n}$ & Mean \pm SD & Minimum & Maximum & Median \\
$\begin{array}{c}\text { IBB } \\
\text { (TLt+TClt) }\end{array}$ & 17 & $1167,20 \pm 239,39$ & 961 & 1913 & 1092,00 \\
$\begin{array}{c}\text { DBB } \\
\text { (TCDt) }\end{array}$ & 17 & $892,73 \pm 116,21$ & 646 & 1057 & 914,00 \\
\hline
\end{tabular}

Time in seconds.

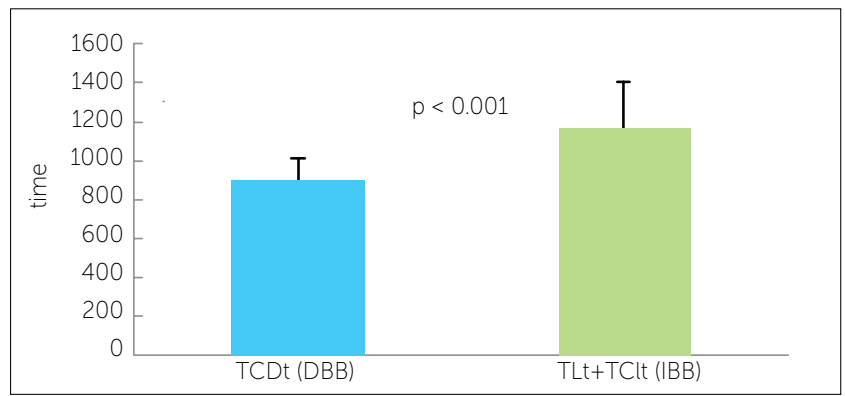

Figure 4 - Comparison of the time spent with IBB (TLt+TCIt) and DBB (TCDt) in the maxilla and the mandible.

Table 4 - Total time spent for laboratorial and clinical steps with IBB (TPBt+TCIt) and DBB (TCDt)

\begin{tabular}{cccccc}
\hline Time & n & Mean \pm SD & Minimum & Maximum & Median \\
$\begin{array}{c}\text { IBB } \\
\text { (TPBt+TCIt) }\end{array}$ & 17 & $885,87 \pm 149,31$ & 720 & 1296 & 842,00 \\
\hline DBB (TCDt) & 17 & $892,73 \pm 116,21$ & 646 & 1057 & 914,00 \\
\hline
\end{tabular}

Time in seconds

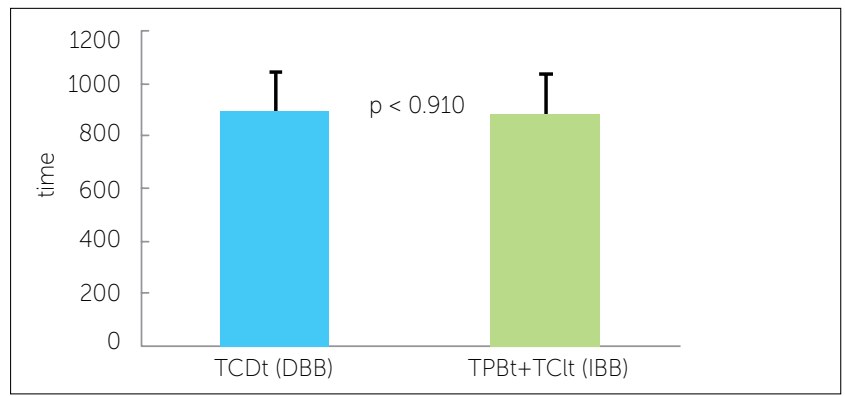

Figure 6 - Comparison of the time spent during laboratorial and clinical steps with IBB (TPBt+TCIt) and DBB (TCDt).

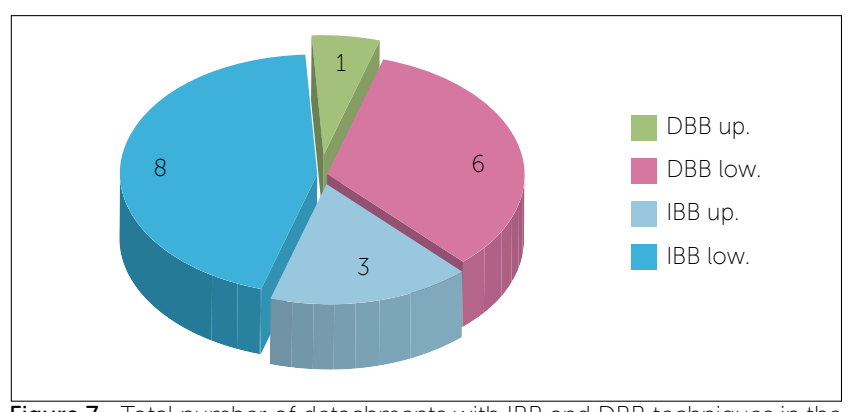

Figure 7 - Total number of detachments with IBB and DBB techniques in the maxilla and the mandible.
Table 3 - Total time spent with IBB (TLt+TCIt) and DBB (TCDt) in both arches, for clinical steps.

\begin{tabular}{cccccc}
\hline Time & n & Mean \pm SD & Minimum & Maximum & Median \\
\hline IBB (TCIt) & 17 & $380,13 \pm 47,59$ & 315 & 489 & 376,00 \\
DBB (TCDt) & 17 & $892,73 \pm 116,21$ & 646 & 1057 & 914,00 \\
\hline
\end{tabular}

Time in seconds.

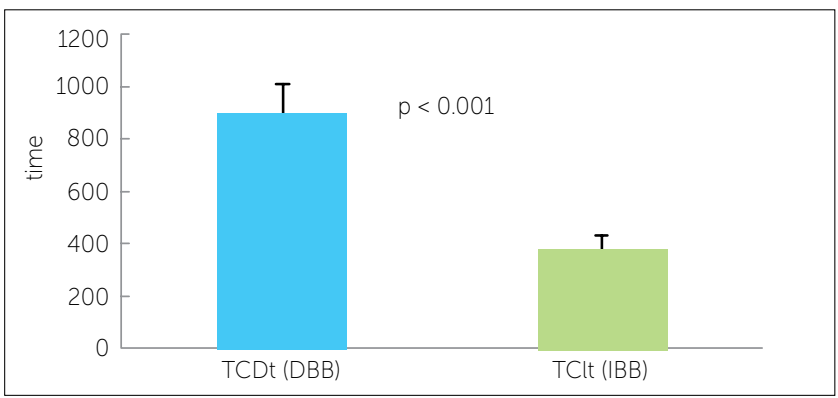

Figure 5 - Comparison of the time spent with IBB (TCIt) and DBB (TCDt) in the maxilla and the mandible during clinical step.

Table 5 - Distribution of the total number of loose brackets in maxilla and mandible regarding time and teeth.

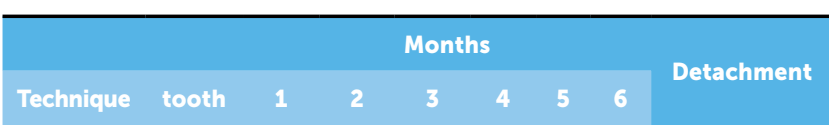

\begin{tabular}{|c|c|c|c|c|c|c|c|c|}
\hline \multirow{5}{*}{ IBB } & 25 & & & & & & & 0 \\
\hline & 24 & & & & & 1 & & 1 \\
\hline & 23 & & & & & 1 & & 1 \\
\hline & 22 & & & & & & & 0 \\
\hline & 21 & & & 1 & & & & 1 \\
\hline \multirow{5}{*}{ DBB } & 11 & & & & & & & 0 \\
\hline & 12 & & & & & 1 & & 1 \\
\hline & 13 & & & & & & & 0 \\
\hline & 14 & & & & & & & 0 \\
\hline & 15 & & & & & & & 0 \\
\hline \multirow{5}{*}{ IBB } & 35 & 1 & & & & & & 1 \\
\hline & 34 & 1 & & & & & & 1 \\
\hline & 33 & 2 & & & & & & 2 \\
\hline & 32 & 1 & & & & & & 1 \\
\hline & 31 & 2 & 1 & & & & & 3 \\
\hline \multirow{5}{*}{ DBB } & 41 & & & & 1 & & & 1 \\
\hline & 42 & & & 1 & & & & 1 \\
\hline & 43 & 2 & & & & & & 2 \\
\hline & 44 & & & & & & & 0 \\
\hline & 45 & & & & 1 & & 1 & 2 \\
\hline Detach. & & 9 & 1 & 2 & 2 & 3 & 1 & 18 \\
\hline
\end{tabular}


and clinical steps) was significantly longer than that with the DBB approach, which is in agreement with other authors ${ }^{3,6-9}$. The mean total time for IBB (TLt+TCIt) was 1167.20 seconds, nearly 19.46 minutes to conclude the process from the central incisor to the second premolar at the left side (maxilla and mandible). If this value were doubled, a total of 38.92 minutes would be spent to complete de IBB procedure in the whole mouth.

As for the DBB technique, a mean time of 892.73 seconds was used to complete the process (TCDt), nearly 14.88 minutes for bonding from the central incisor to the second premolar at the right side (maxilla and mandible). Again, if this value were double, a total of 29.76 minutes would be necessary to accomplish the DBB procedure in the whole mouth.

Thus, the time spent with both IBB and DBB techniques in the present study was shorter than that reported by other researches. ${ }^{7,9}$ In this sense, the IBB procedure can be considered faster due to being considered as an easy technique, demanding fewer laboratorial steps and being clinically applied with ease.

With regard to the clinical phase, the present study revealed that the IBB technique was significantly less time-consuming than the DBB. ${ }^{8-11}$ A mean of 380.13 seconds was necessary to complete the clinical procedure with the IBB (TCIt), representing about 6.33 minutes. Thus, based on the same analogy described previously, the procedure would be completed in 12.68 minutes for the whole mouth. Considering that the total time (laboratorial and clinical steps) for both jaws (maxilla and mandible) was 38.92 minutes, the laboratorial phase represents $67.50 \%$ of the IBB technique. However, trained assistants could carry out some of these procedures (fabrication and cleaning of the transferring tray), reducing the difference between IBB and DBB approaches. ${ }^{11}$

As for DBB, the mean total time in both jaws was 29.76 minutes, longer than time used to perform the clinical step with IBB (12.68 minutes). Thus, the $\mathrm{IBB}$ is advantageous in comparison to the DBB since it reduces chair-time for bracket bonding, minimizes clinical stress and increases patient's comfort. ${ }^{11}$

It is important to highlight that the time spent to make the working casts was not considered since it can be obtained at the same session in which diagnostic casts are made or even at a dental radiology center. However, the other laboratorial steps could not be disregarded.

As for loose brackets, the results demonstrated a value of $5.92 \%$ during a 24 -week follow-up, which was similar to previous studies. ${ }^{7,912-13}$ It has been suggested that there is no statistically significant difference between the IBB and $\mathrm{DBB}$ techniques regarding the retention of brackets bonded to human enamel. ${ }^{14,15,16}$

In this sense, the lower teeth exhibited more failures than the upper teeth., ${ }^{7,17,19}$ However, the anterior teeth presented more detachments in comparison to the posterior teeth, which is in disagreement with other studies. ${ }^{17-20}$ Considering the analysis of the results and the clinical aspects that could result in a higher prevalence of failure in the lower anterior teeth, it was concluded that this data was specific for the present sample. The loose brackets may have been caused by failure during initial impression or positioning (DBB), failure during laboratorial step (IBB), poor tooth polishing, failure during acid etching, poor control of humidity, several contaminations (saliva and blood), improper occlusion (contact with orthodontic accessories), repeated trauma (hard food), and enamel quality. ${ }^{21}$

Considering the literature and the present results, it was observed that the IBB technique is advantageous in comparison to the DBB approach due to easy laboratorial procedure, accurate brackets positioning, reduced chair-time and clinical stress, and multidisciplinary accomplishment (orthodontist and assistants).

\section{CONCLUSIONS}

The total time spent with the DBB technique was shorter than that with the IBB approach. However, the clinical step took less time with IBB in comparison to $\mathrm{DBB}$. The time spent for laboratorial positioning of the brackets and clinical insertion with IBB was similar to that observed with DBB, which justifies the advantages of the IBB technique in comparison to the $\mathrm{DBB}$ procedure.

Both approaches (IBB and DBB) exhibited similar prevalence of loose bracket and the highest number of failures occurred in the lower jaw. 


\section{REFERENCES}

1. Reynolds IR. A review of direct orthodontic bonding. Br J Orthod. 1975:2(3):171-8

2. Wertz RA. Beginning bonding - state of the art. Angle Orthod $1980 ; 50(3): 245-7$

3. Thomas RG. Indirect bonding: simplicity in action. J Clin Orthod. 1979;13(2):93-106.

4. Brandt S, Servoss JM, Wolfson J. Practical methods of bonding, direct and indirect. J Clin Orthod. 1975:9(10):610-35

5. Silverman E, Cohen M, Gianelly A, Dietz V. A universal direct bonding system for both metal and plastic brackets. Am J Orthod Dentofacial Orthop. 1972:62(3):235-44.

6. White LW. A new and improved indirect bonding technique. J Clin Orthod. 1999:33(1):17-23

7. Aguirre MJ, King GJ, Waldron JM. Assessment of bracket placement and bond strength when comparing direct bonding and indirect bonding techniques. Am J Orthod. 1982;82(4):269-76.

8. Fried KH, Newman GV. Indirect bonding with a no-mix adhesive. J Clin Orthod. 1983;17(6):414-7.

9. Scholz RP. Indirect bonding revisited. J Clin Orthod. 1983:17(8):529-36

10. Reichheld S, Ritucci R, Gianelly A. An indirect bonding technique. J Clin Orthod. 1990:24(1):21-4

11. Hickham JH. Predictable indirect bonding. J Clin Orthod. 1993:27(4):215-7

12. Beech DR, Jalaly T. Clinical and laboratory evaluation of some orthodontic direct bonding systems. J Dent Res. 1981;60(6):972-7.
13. Miles PG, Weyant RJ. A comparison of two indirect bonding adhesives. Angle Orthod. 2005:75(6):1019-23.

14. Yi GK, Dunn WJ, Taloumis LJ. Shear bond strength comparison between direct and indirect bonded orthodontic brackets. Am J Orthod Dentofacial Orthop. 2003:124(5):577-81

15. Thiyagarajah S, Spary DJ, Rock WP. A clinical comparison of bracket bond failures in association with direct and indirect bonding. J Orthod. 2006:33(3):198-204

16. Deahl ST, Salome N, Hatch JP, Rugh JD. Practice-based comparison of direct and indirect bonding. Am J Orthod Dentofacial Orthop. 2007;132(6):738-42

17. Knoll M, Gwinnet AJ, Wolff MS. Shear strength of brackets bonded to anterior and posterior teeth. Am J Orthod Dentofacial Orthop. 1986:89(6):476-9

18. Sondhi A. Efficient and effective indirect bonding. Am J Orthod Dentofacial Orthop. 1999:115(4):352-9.

19. Linklater RA, Gordon PH. Bond failure patterns in vivo. Am J Orthod Dentofacial Orthop. 2003:123(4):534-9.

20. Langlade M. Terapêutica ortodôntica. 3a ed. São Paulo: Ed. Santos; 1992.

21. Kinch AP, Taylor H, Warltier R, Oliver RG, Newcombe RG. A clinical trial comparing the failures rates of directly bonded brackets using etch times of 15 or 60 seconds. Am J Orthod Dentofacial Orthop. 1988;94(6):476-83. 